Geological Society, London, Special Publications

The complexity of 3D stress-state changes during compressional tectonic inversion at the onset of orogeny

Koen Van Noten, Hervé Van Baelen and Manuel Sintubin

Geological Society, London, Special Publications 2012, v.367; p51-69.

doi: $10.1144 /$ SP367.5

$\begin{array}{ll}\text { Email alerting } & \text { click here to receive free e-mail alerts when } \\ \text { service } & \text { new articles cite this article } \\ \text { Permission } & \text { click here to seek permission to re-use all or } \\ \text { request } & \text { part of this article } \\ \text { Subscribe } & \text { click here to subscribe to Geological Society, } \\ & \text { Condon, Special Publications or the Lyell } \\ & \text { Collection }\end{array}$

Notes

(C) The Geological Society of London 2012

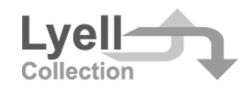




\title{
The complexity of 3D stress-state changes during compressional tectonic inversion at the onset of orogeny
}

\author{
KOEN VAN NOTEN ${ }^{1,2}$, HERVÉ VAN BAELEN ${ }^{1} \&$ MANUEL SINTUBIN ${ }^{1 *}$ \\ ${ }^{1}$ Geodynamics and Geofluids Research Group, Department of Earth and Environmental \\ Sciences, Katholieke Universiteit Leuven, Celestijnenlaan 200E, B-3001 Leuven, Belgium \\ ${ }^{2}$ Present address: Seismology Section, Royal Observatory of Belgium, Ringlaan 3, \\ B-1180 Brussels, Belgium
}

*Corresponding author (e-mail: manuel.sintubin@ees.kuleuven.be)

\begin{abstract}
Compressional tectonic inversions are classically represented in 2D brittle failure mode (BFM) plots that illustrate the change in differential stress $\left(\sigma_{1}-\sigma_{3}\right)$ versus the pore-fluid pressure during orogenic shortening. In these BFM plots, the tectonic switch between extension and compression occurs at a differential stress state of zero. However, mostly anisotropic conditions are present in the Earth's crust, making isotropic stress conditions highly questionable. In this study, theoretical 3D stress-state reconstructions are proposed to illustrate the complexity of triaxial stress transitions during compressional inversion of Andersonian stress regimes. These reconstructions are based on successive late burial and early tectonic quartz veins which reflect early Variscan tectonic inversion in the Rhenohercynian foreland fold-and-thrust belt (High-Ardenne Slate Belt, Belgium, Germany). This theoretical exercise predicts that, no matter the geometry of the basin or the orientation of shortening, a transitional 'wrench' tectonic regime should always occur between extension and compression. To date, this intermediate regime has never been observed in structures in a shortened basin affected by tectonic inversion. Our study implies that stress transitions are therefore more complex than classically represented in 2D. Ideally, a transitional 'wrench' regime should be implemented in BFM plots at the switch between the extensional and compressional regimes.
\end{abstract}

Extension (Mode I) fractures are classically interpreted to form at low differential stresses less than four times the tensile strength $(T)$ of rock (e.g. Secor 1965). They open perpendicular to the minimum principal stress $\left(\sigma_{3}\right)$ and propagate in the plane of the maximum $\left(\sigma_{1}\right)$ and intermediate $\left(\sigma_{2}\right)$ principal stresses. The alignment of fractures has therefore often been used in orogenic belts to determine the orientation of the palaeostress field at the time of fracturing (Cox et al. 2001; Gillespie et al. 2001; Laubach et al. 2004). If veins which initiated as extension fractures are uniform in trend over a large area, then they can also be used as such a palaeostress indicator (e.g. Boullier \& Robert 1992; Cosgrove 2001; Gillespie et al. 2001; Mazzarini et al. 2010; Van Noten \& Sintubin 2010). Different cross-cutting or successive vein generations are even more interesting because they have the potential (1) to serve as a tool to decipher changes in the overall stress regime during multiple phases of fracturing and (2) to define the $P-T$ conditions at which these stress changes occurred. On the one hand, different crosscutting fracture and/or vein generations have been used in many studies to deduce local stress field rotation in a consistent remote stress regime (Jackson 1991; Crespi \& Chan 1996; Stowell et al. 1999;
Laubach \& Diaz-Tushman 2009; Wiltschko et al. 2009). On the other hand, successive cross-cutting veins (i.e. vein sets that are oriented differently with respect to bedding) have often been used to determine a transition in regional stress regime from extension to compression or reversely (Manning \& Bird 1991; Boullier \& Robert 1992; Teixell et al. 2000; Hilgers et al. 2006b; Van Noten et al. 2008, 2011; Laubach \& Diaz-Tushman 2009). Alternatively, cross-cutting vein sets are observed in close relationship to faults in which they represent fluctuating fluid pressures during fault-valve activity and are related to short-lived local stress transitions in a consistent remote stress regime (Boullier \& Robert 1992; Sibson 1995; Nielsen et al. 1998; Muchez et al. 2000; Collettini et al. 2006). Local mutually cross-cutting vein sets may also develop in the presence of mechanical anisotropy around fault planes in a consistent remote stress field (Healy 2009; Fagereng et al. 2010). In all these studies, transitions between regional stress regimes are defined as tectonic inversions; a positive (compressional) tectonic inversion corresponds to a transition from an extensional to a compressional stress regime, while a negative (extensional) tectonic inversion reflects the transition from compression to extension. 
The conditions of brittle failure of an isotropic rock have classically been visualized in a MohrCoulomb diagram, relating the shear $(\tau)$ and the normal stress $\left(\sigma_{\mathrm{n}}\right)$ on a particular plane of failure with a particular orientation to the stress state (represented by principal stresses). Although MohrCoulomb diagrams provide an excellent way to illustrate both the relationship between stress magnitudes and differential stress, and which type of fracture will develop (i.e. extension, extensionalshear or shear fractures) (Cosgrove 1995), they are limited to illustrate a specific stress state at a specific moment. Unfortunately, the evolution of the fluid pressure $\left(P_{\mathrm{f}}\right)$ during orogeny can only be illustrated by means of successive Mohr circle reconstructions. Sibson $(1998,2000)$ introduced the concept of 2D brittle failure mode plots (BFM plots; Fig. 1) which allow a more dynamic and evolutionary analysis of brittle structures than possible in a classical Mohr-Coulomb diagram. In these BFM plots the transition of Andersonian stress regimes at a certain depth is visualized by means of the change of differential stress versus the evolution of the pore-fluid factor $\left(\lambda_{\mathrm{v}}\right)$ and the effective vertical stress $\left(\sigma_{\mathrm{V}}^{\prime}=\sigma_{\mathrm{V}}-P_{\mathrm{f}}\right)$. Moreover, they illustrate a change in Andersonian stress orientations during

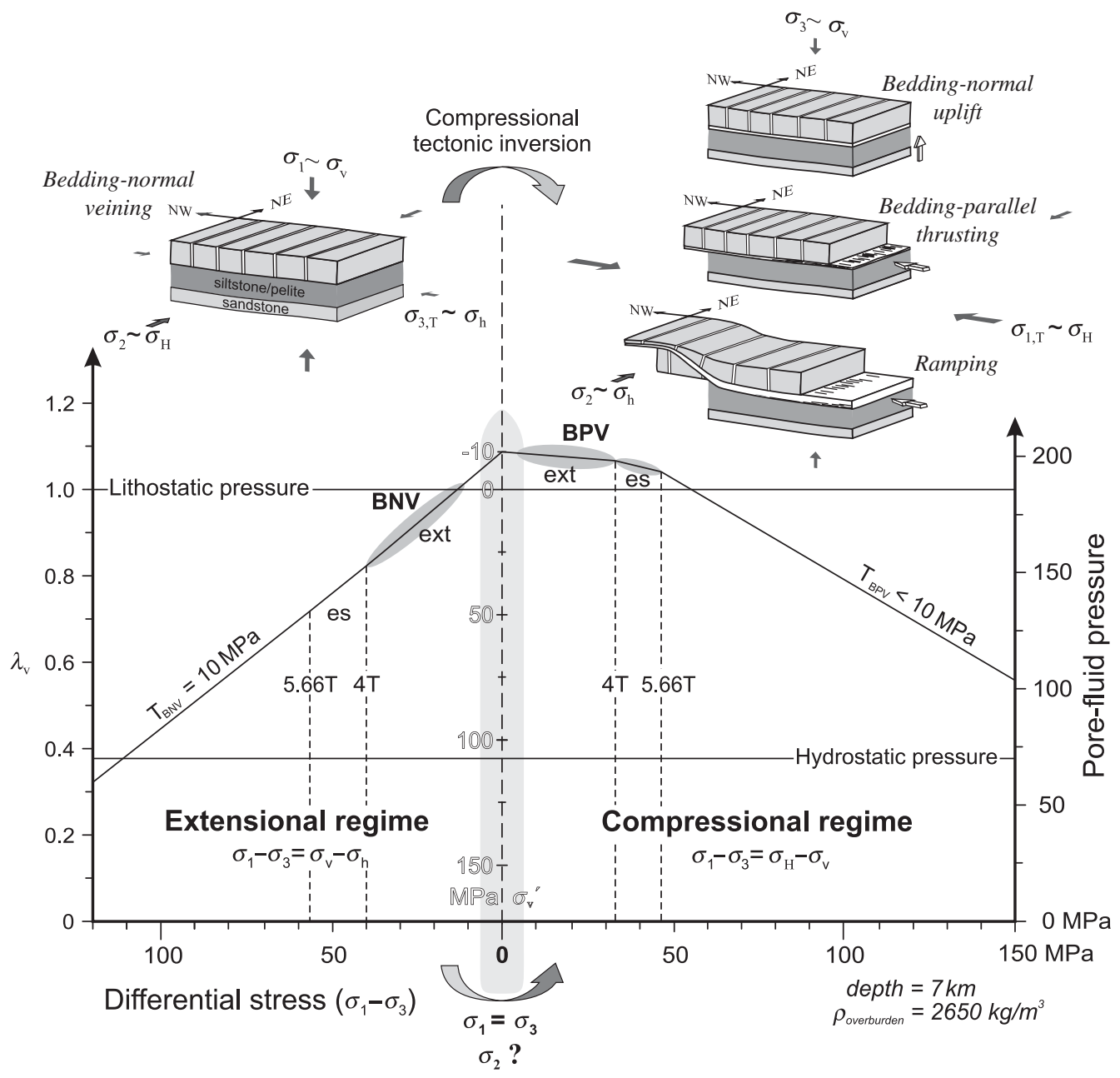

Fig. 1. Example of a 2D brittle failure mode plot (after Sibson 2004) which illustrates the evolution of fluid (over)pressure during compressional tectonic inversion, applied on the emplacement of two successive vein sets oriented normal and parallel to bedding in the High-Ardenne case study (after Van Noten et al. 2011). The effect of $\sigma_{2}$ at the time of the tectonic inversion $\left(\sigma_{1}-\sigma_{3}=0\right.$; grey area) is not illustrated in these mode plots and forms the research question of this study. 
tectonic inversion in which a vertical $\sigma_{1}$ switches to horizontal during compressional inversion, while $\sigma_{3}$ has an opposite reorientation from horizontal to vertical. BFM plots are useful to visualize parameters such as the tensile strength $(T)$ of rock or the friction along faults $(\mu)$ which strongly influence the maximum overpressure that can be built up during tectonic inversion (Cox 2010). The layout of BFM plots is designed to illustrate contrasting failure conditions which may be expected from the transitions between two stress regimes (Sibson 2004). Although these plots are originally constructed to understand the development and evolution of fault systems with their associated vein sets and are used in a wide range of tectonic settings, they are also very useful to define the relative timing of vein formation in terms of changing differential stress during tectonic inversion (Van Noten et al. 2011). Sibson (2004) and Cox (2010) moreover illustrate that the interaction between changes in the tectonic stress regime, fluid-pressure changes and fluid migration during tectonic inversion are important for the genesis of ore deposits (e.g. Tunks et al. 2004). A better understanding of the link between stress-state transitions during mountain-building processes and ore genesis could therefore have major economic implications (cf. Blundell 2002).

As illustrated on the BFM plot and shown by several studies (e.g. Sibson 1995, 2004), fluid overpressures are likely to develop during the transition from extension to compression and are easier to maintain at low differential stress in the compressional regime than in the extensional regime. Due to low differential stress during tectonic inversion, fluid overpressures are mostly captured in extensional or in extensional-shear veins that accompany the tectonic inversion. These extension veins have a vertical orientation in the extensional regime and a horizontal orientation in the compressional regime at the time of fracturing. The tectonic switch, which is illustrated on the BFM plot mode by the line at zero differential stress (see Fig. 1), reflects the specific stress state at which $\sigma_{1}$ equals $\sigma_{3}$ (so that $\sigma_{1}-\sigma_{3}=0$ ) without considering the role of $\sigma_{2}$. A zero differential stress-state can therefore only be reached in a state of isotropic pressure $\left(\sigma_{1}=\sigma_{2}=\sigma_{3}\right)$ during the tectonic switch. The chances that a stress state equals a pure pressure state in the brittle upper crust are, however, questionable (e.g. Healy 2009). Because of the assumption of an isotropic pressure, the stress-state evolution illustrated in BFM plots is actually an oversimplification of the true 3D stress-state evolution in the Earth's crust. In more realistic anisotropic conditions, the transition from extensional to compressional might therefore be more complex due to the fact that a triaxial stress state might remain present during inversion. Sibson (1998) mentioned that the brittle failure curves for an intermediate wrench regime $\left(\sigma_{2} \sim \sigma_{\mathrm{V}}\right)$ lie anywhere at the zero differential stress line between the extensional and compressional plots, depending on the value of $\sigma_{2}$ with respect to $\sigma_{1}$ and $\sigma_{3}$. To date, however, this intermediate regime has been ignored in any tectonic inversion model.

In this study, we analyse possible stress-state evolutions to illustrate the complexity of 3D stress transitions during compressive tectonic inversion, based on the geometric and kinematic analysis of late-burial bedding-normal and successive early tectonic bedding-parallel quartz veins which occur in the frontal part of the Rhenohercynian foreland fold-and-thrust belt (High-Ardenne Slate Belt, Belgium, Germany). These successive vein sets indicate an important fluid-assisted deformation during the Early Variscan (Early Carboniferous) tectonic inversion affecting the Ardenne-Eifel basin at the onset of Variscan Orogeny. By means of different scenarios, it is illustrated that both the intermediate principal stress $\sigma_{2}$ and the increasing tectonic stress $\sigma_{\mathrm{T}}$ plays an important role during tectonic inversion in anisotropic stress conditions, and that a zero differential stress state is not necessarily reached during inversion. It is shown that stress transitions are commonly more complex than classically interpreted. Although the starting point of this theoretical exercise is based on a case study, the application of 3D stress transitions under triaxial stress conditions may have a wide range of implications with respect to the evolution of dynamic permeability during orogenic shortening.

\section{Geological framework: the High-Ardenne case study}

\section{Geological setting}

The dataset on which the present exercise on the complexity of 3D stress transitions during tectonic inversion is based, comprises two successive sets of extensional quartz veins that occur in Lower Devonian siliciclastic multilayers. The study area is situated in the frontal part of the Rhenohercynian foreland fold-and-thrust belt, more specifically in the High-Ardenne slate belt (Belgium, Germany), which forms together with the Dinant fold-andthrust belt and several Lower Palaeozoic (CambroOrdovician) inliers, part of the Ardenne allochton (Fig. 2). This allochton has been thrust over the Brabant parautochton during the latest Asturian stage of the Variscan Orogeny (Late Carboniferous, Meilliez \& Mansy 1990). The host-rock lithologies, competent sandstones, psammites and quartzites, alternating with incompetent siltstone and pelites, 


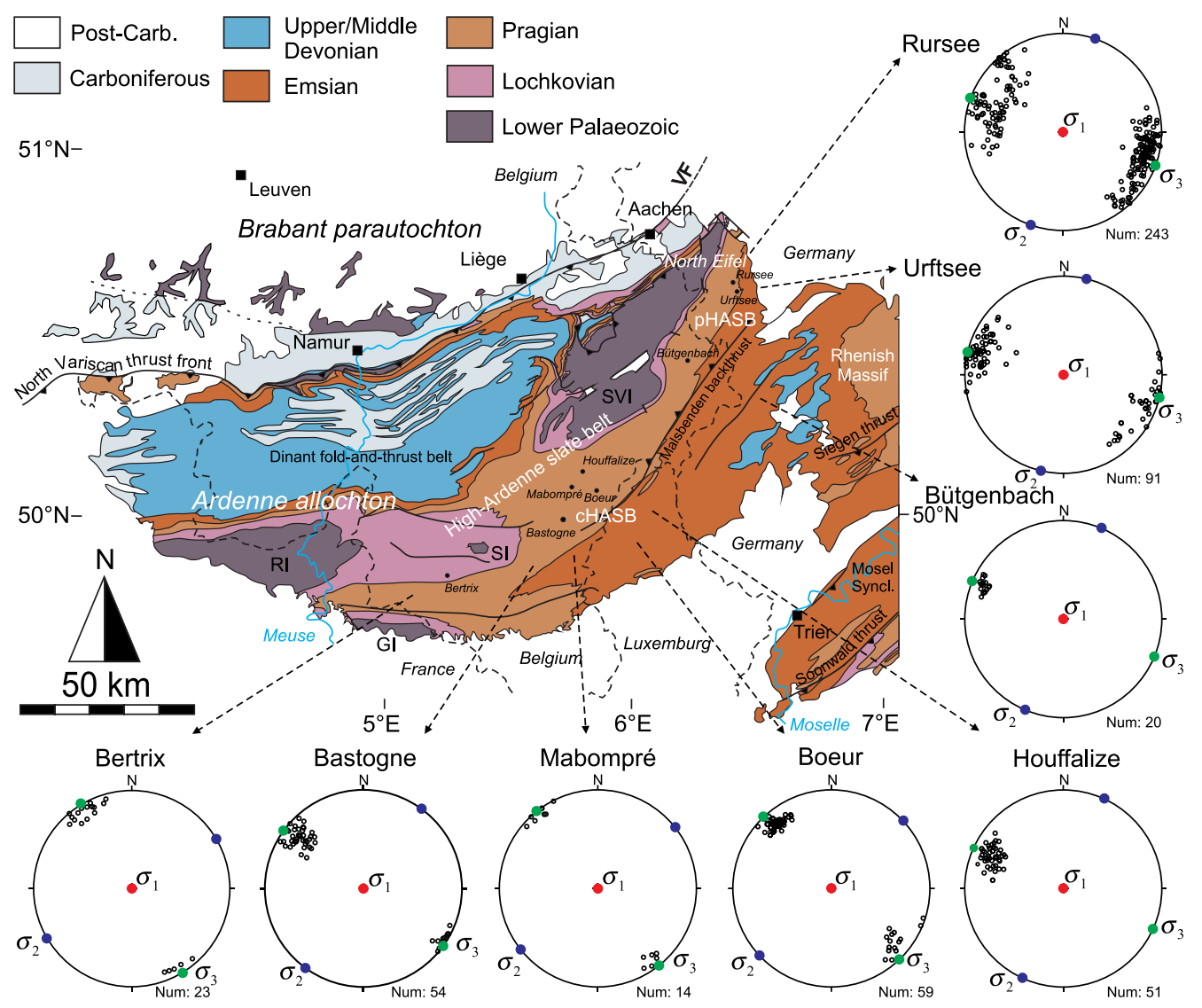

Fig. 2. Structural map and palaeostress analysis of bedding-normal quartz veins in the High-Ardenne slate belt (Belgium, Germany). The lower-hemisphere, equal-area stereographic projections show the original orientation of the veins prior to folding and reflect a consistent extensional stress field at the time of veining. The slight rotation of the $\sigma_{1}-\sigma_{2}$ plane from NE-SW in the SW to NNE-SSW in the NE of the slate belt can be attributed to postveining oroclinal bending of the slate belt related to the NW-SE-directed Variscan compression.

reflect a Lower Devonian shallow marine deltaic deposition (Stets \& Schafer 2009) in the ArdenneEifel basin that developed on the passive margin of the Rhenohercynian Ocean. The rocks are affected by very-low-grade to low-grade metamorphism that was pre- to synkinematic to the prograding Variscan deformation but is considered to be primarily of burial origin (Fielitz \& Mansy 1999). Metamorphic conditions vary from epizonal in the deepest part $(10 \mathrm{~km})$ of the shortened sedimentary Ardenne-Eifel basin (Kenis et al. 2002, 2005) to anchizonal in the shallower parts that reflect burial conditions of $7 \mathrm{~km}$ (von Winterfeld 1994; Van Noten et al. 2011). The deepest parts are currently exposed in the central part of the High-Ardenne Slate Belt, while the higher structural levels are present in the North Eifel in the north-eastern periphery of the slate belt (Fig. 2).

\section{Successive vein sets}

Two successive quartz vein sets are considered to reflect the Early Variscan (Early Carboniferous) compressional tectonic inversion of the Ardenne-Eifel sedimentary basin. A first prefolding and precleavage set of veins is oriented perpendicular to bedding and is regionally distributed in the Lower Devonian sequences of the High-Ardenne slate belt. These prefolding bedding-normal veins are mostly confined to competent layers (Fig. 3a) and are regionally consistent in orientation, after restoring the beds to their original orientation prior to the formation of folds (Fig. 2). They are determined to be extension veins that formed in the extensional regime during the latest part of the burial. A limited compressibility of the competent host-rock at the time of veining is exemplified by (1) 


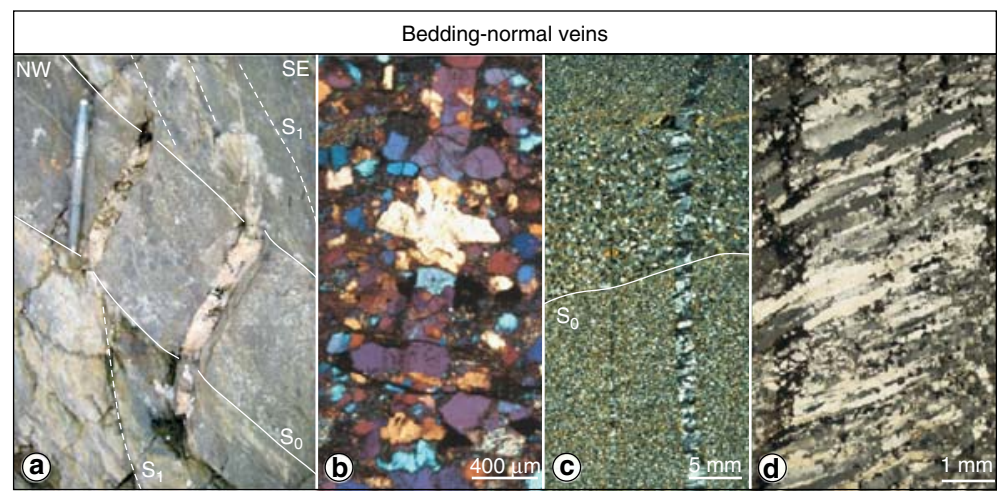

Fig. 3. Characteristics of bedding-normal quartz veins. (a) Veins oriented perpendicular to bedding and refracted at the sandstone-siltstone interface, similar to cleavage. (b) Transgranular, millimetre-thin vein fracturing through the host-rock grains. (c) Millimetre-thin vein with fibrous quartz infill. (d) Fibrous quartz crystals spanning the vein walls. Ataxial vein growth.

transgranular microveins with a low tortuosity (Fig. 3b), demonstrating that fracturing is not affected by the grain-scale heterogeneity of the competent host-rock and (2) the absence of buckled veins which suggests that subsequently, no postveining compaction occurred (Fig. 3c). The vein infill mostly contains a fibrous fabric (Fig. 3d) in which crack-seal microstructures are often present. Furthermore, it has been demonstrated by means of a combined (micro)structural and microthermometric study of fluid inclusions in vein quartz that these extension veins initiated at elevated, up to lithostatic, fluid pressures under low differential stress and that they result from several phases of fracturing and sealing (Van Noten et al. 2009, 2011). Maximum pore-fluid overpressures of $c .190 \mathrm{MPa}$ are measured for the bedding-normal veins in the North Eifel, exceeding a lithostatic pressure of $c .185 \mathrm{MPa}$ and reflecting the pressure at a burial depth of $7 \mathrm{~km}$ (Van Noten et al. 2011). This regional occurrence of overpressures at the time of vein formation suggests that the Ardenne-Eifel basin can be considered as an exposed example of a $350 \mathrm{Ma}$ fractured reservoir, composed of sequences of interbedded high-pressure compartments (Hilgers et al. 2006a; Kenis \& Sintubin 2007). An initial increasing tectonic stress $\sigma_{\mathrm{T}}$ at the onset of Variscan Orogeny has been invoked as the driving mechanism (1) to decrease the differential stress at the latest stages of the burial and (2) to generate lithostatic overpressures, both of which are necessary to form vertical extension veins in the extensional regime. The initial tectonic stress may be considered as the driving force for the stagnating extension at the end of the extensional regime.

In the higher structural levels of the HighArdenne slate belt, currently exposed in the North
Eifel (Germany; Fig. 2), bedding-normal veins are succeeded and cross-cut by bedding-parallel quartz veins which reflect bedding-normal uplift (Fig. 4a) and bedding-parallel thrusting (Fig. 4b) at the onset of folding during the initial stages of the compressional tectonic regime. Microstructural analysis of their typical laminated fabric (i.e. blocky and crackseal quartz laminae intercalated by host-rock inclusion lines; Fig. 4c) reveals that they have been formed during successive cycles of uplift and collapse. Repetitive host-rock inclusion bands parallel to bedding (in the crack-seal laminae; Fig. 4c) result from repetitive fracturing and sealing by the crack-seal mechanism (Ramsay 1980) and are supportive for defining these bedding-parallel veins as extension veins. While the orientation of repetitive quartz laminae parallel to bedding (Fig. 4c) clearly reflect bedding-normal uplift, bedding-parallel stylolites (Fig. 4d) reflect bedding-normal collapse between the multiple phases of fracturing and sealing that can possibly be linked to the earthquake cycle (cf. Cox 1987) and to fault-valving during vein development (Sibson 1990; Cox 1995). Additionally, the pronounced bedding-parallel fabric of the bedding-parallel veins shows robust evidence for bedding-parallel shearing prior to folding. This is indicated by bedding-parallel veins cross-cutting layers in small ramps (Fig. 4e). These veins which bear evidence of thrusting are therefore classified as extensional-shear veins which reflect beddingparallel movements during progressive orogenic shortening. Microthermometric analysis of fluid inclusions shows that these bedding-parallel veins are induced at a supralithostatic fluid pressure $(c$. $205 \mathrm{MPa}$ ) (Van Noten 2011; Van Noten et al. 2011).

The presence of these vein sets illustrates an important fluid-assisted deformation in the brittle 

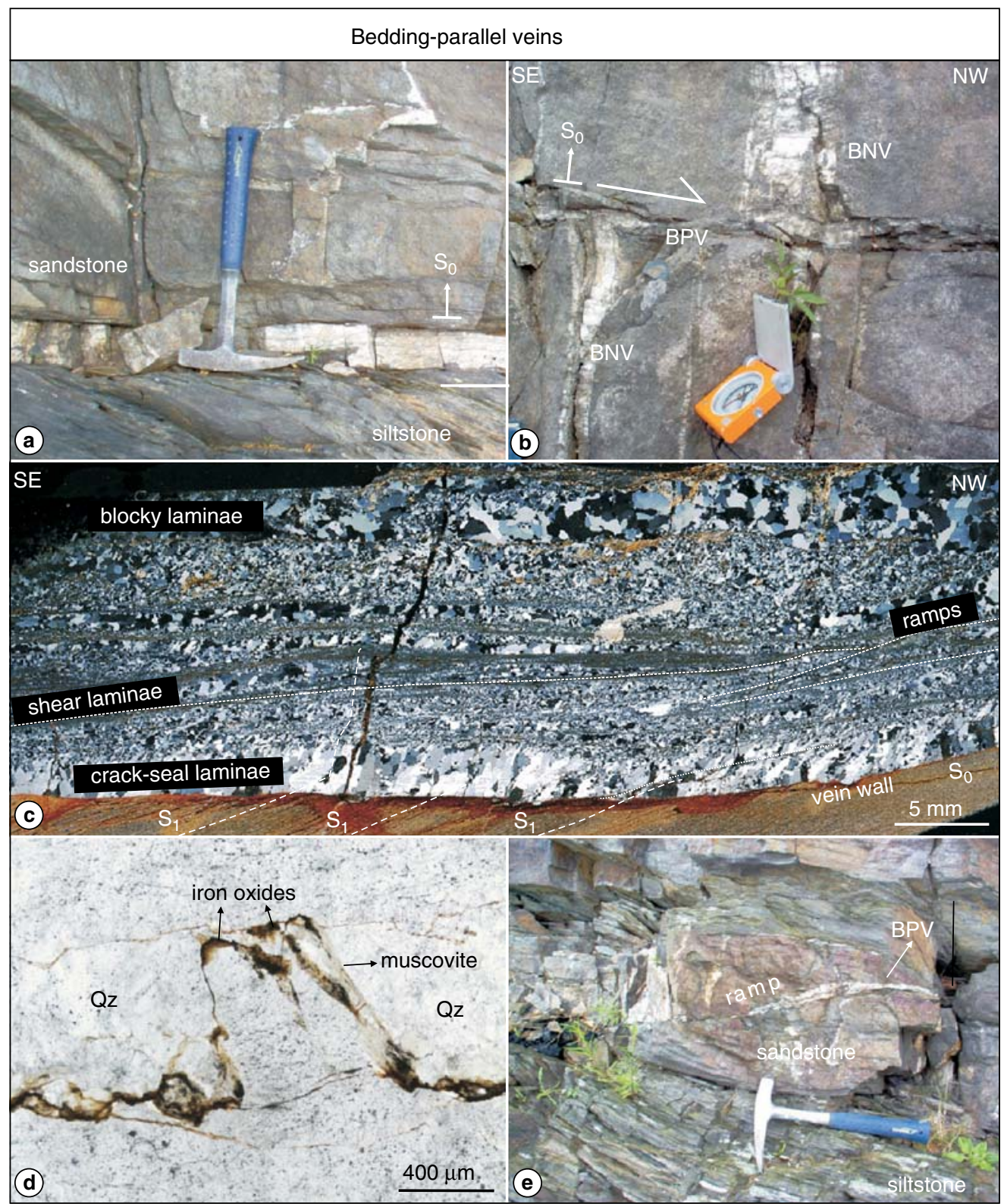

Fig. 4. Characteristics of bedding-parallel quartz veins (BPV). (a) Vein situated between sandstone and siltstone. (b) Vein cross-cutting and offsetting a bedding-normal vein. (c) Blocky and crack-seal quartz laminae intercalated with host-rock inclusions lines and shear laminae in a centimetre-thin laminated vein. Laminae show a pronounced top-to-the-NW bedding-parallel shear along small-scale ramps. (d) Anastomosing stylolite observed in the vein containing muscovite and iron oxides. (e) Small-scale thrust accompanied by a quartz vein cross-cutting a coarse-grained sandstone.

upper crust during the Early Carboniferous tectonic inversion affecting the Ardenne-Eifel basin at the onset of Variscan Orogeny. In contrast to these two important vein-forming events at the onset of the orogeny, quartz veining seems to have occurred rather occasionally during the main compressional stage of the Variscan Orogeny and is restricted to faulting and local boudinage of competent layers 
(e.g. Van Baelen \& Sintubin 2008). The Late Variscan negative (extensional) tectonic inversion is locally exemplified in the High-Ardenne slate belt (Bertrix, Herbeumont, Belgium) by subvertical discordant extension quartz veins that formed closely after the tectonic inversion and underwent a shape modification during progressive shearing, reflecting the destabilization of the Variscan Orogen (Van Baelen 2010). It has been proven by several microthermometric analyses of fluid inclusions that the geothermal gradient - and thus the temperaturedepth conditions during the positive tectonic inversion (Kenis et al. 2005; Van Noten 2011), the main Variscan compression (Fielitz \& Mansy 1999) and during the Variscan destabilization after negative inversion (Van Baelen 2010) - remained constant. This implies that (1) no significant subsidence or uplift of the shortened Ardenne-Eifel basin occurred during the whole Variscan Orogeny and (2) the magnitude of $\sigma_{\mathrm{V}}$ remained constant during both positive and negative Variscan tectonic inversion.

\section{Palaeostress analysis}

The regional occurring bedding-normal veins are determined to be extension veins that formed in the extensional regime at the latest stages of the burial. If rotated to their original prefolding orientation (cf. method of Debacker et al. 2009) they are more or less consistent in orientation across the whole High-Ardenne slate belt (Fig. 2). The veins, which were nearly vertical at the time of vein formation, originally range from $\mathrm{NE}-\mathrm{SW}$ in the $\mathrm{SW}$ and central part of the High-Ardenne slate belt (Bertrix, Bastogne, Mabompré, Boeur; Fig. 2) to NNE-SSW towards the NE-part (Houffalize, Bütgenbach, Urftsee, Rursee; Fig. 2). This structural change is probably related to a post-veining oroclinal bending of the slate belt during the main Variscan contraction because of the presence of a rigid basement in the north (cf. Brabant parautochton in Fig. 2; Fielitz 1992; Mansy et al. 1999). Notwithstanding this oroclinal bending, the extension veins can be used as a regional palaeostress indicator for the stress state during the extensional regime. The orientation of the principal stress axes is derived from the distribution of extension veins that are assumed to form perpendicular to $\sigma_{3}$ and align in the $\sigma_{1}-\sigma_{2}$ plane. Veins are therefore formed in a consistent anisotropic Andersonian stress field that is characterized by a vertical $\sigma_{1}$, corresponding to the overburden stress $\sigma_{\mathrm{V}}$, and two well-defined horizontal principal stresses $\left(\sigma_{\mathrm{H}}\right.$ and $\left.\sigma_{\mathrm{h}}\right)$, reflecting a triaxial stress state during bedding-normal veining.

After tectonic inversion, bedding-normal vein formation is followed by bedding-parallel veining in the upper structural levels of the High-Ardenne slate belt. In the tectonic switch $\sigma_{3}$ changes to vertical and corresponds to the overburden stress $\sigma_{\mathrm{V}}$, while $\sigma_{1}$ now corresponds to $\sigma_{\mathrm{H}}$ and reflects regional shortening in the compressional regime (Fig. 1). Similar to the bedding-normal veins, the extensional bedding-parallel quartz veins are the brittle expression of the $\sigma_{1}-\sigma_{2}$ plane (cf. Secor 1965 ) and can be used as a palaeostress indicator. Macro- and microstructural analysis of the shear planes in the microfabric of the bedding-parallel veins and NW-SE-trending slickensides on the vein walls have been used to indicate that Variscan shortening occurred in an overall NW-SE-directed compression during bedding-parallel veining. In the compressional regime, veins follow the bedding anisotropy (lower tensile strength because of lower cohesion); in the extensional regime they form in intact rock (higher tensile strength).

Bedding-parallel veining is followed by the formation of NW-verging folds and a SE-dipping axial planar cleavage during Variscan fold-and-cleavage development in the North Eifel (Fielitz 1992; Van Noten et al. 2008). Similar to the North Eifel, the major part of the Rhenish Massif is characterized by a strong $\mathrm{NW}$-directed vergence that reflects an overall NW-SE compression during the main phase of Variscan contraction (Weber 1981).

\section{Basic assumptions as starting point for the reconstruction of $3 \mathrm{D}$ stress transitions}

The orientations of the two vein sets in the North Eifel have been used as a tool to evaluate the stressstate and fluid-pressure evolution of a basin during incipient orogenic shortening. Although the state of stress at the time of veining is well understood, with the two vein sets as the end members reflecting the stress state in the extensional and compressional regime, the switch between two stress regimes has (to date) only been approached from a crust with isotropic stress properties (e.g. Sibson 2000, 2004). From the consistent vein orientation in the extensional regime and in the compressional regime in the High-Ardenne case study it is however already clear that mostly anisotropic stress conditions are present in the Earth's crust. To illustrate the complexity of $3 \mathrm{D}$ stress transitions in a triaxial stress state, we constructed three different scenarios in which a basin with a predefined sedimentary geometry experiences a compressional tectonic inversion induced by a consistently increasing horizontal tectonic stress. In each scenario, we investigate the stress-state evolution of the basin following two options by changing the orientation of $\sigma_{\mathrm{T}}$, causing shortening from a NW-SE to a NE-SW direction. Although the main tectonic compression in the case study was NW-SE, it is still unclear whether the direction of tectonic compression remained 
constant through time or if it has rotated prior to the main deformation.

After presenting these scenarios, we discuss those stress states which are favourable to form the two successive vein sets that are observed in the High-Ardenne case study.

The starting point for constructing these three different scenarios is based on the following questions:

(1) How does a increasing horizontal tectonic stress $\sigma_{\mathrm{T}}$ influence the eventual orientation of extension veins?

(2) Does the initial basin geometry influence the orientation of extension veins (Fig. 5)?

(3) Do veins with a regionally consistent orientation only form in one specific stress regime, or can they occur in several different stress regimes?

(4) What is the effect of the intermediate principal stress $\sigma_{2}$ during inversion?

The different scenarios are exemplified by means of 3D stress-state graphics (Figs 6-8); the longest axis represents $\sigma_{1}$, the intermediate axis $\sigma_{2}$ and the shortest axis $\sigma_{3}$. Each specific stress state during the progressive stress-state changes is reconstructed in a Mohr-Coulomb diagram. Stress abbreviations and symbols used are listed in Table 1 . In order to evaluate the different scenarios during inversion properly, the constraints described in the following sections are assumed.

\section{Constant $\sigma_{V}$ during tectonic inversion}

The 3D stress-state reconstructions are constructed in such a way that $\sigma_{\mathrm{V}}$ is assumed to have a constant magnitude, corresponding to $\sigma_{1}$ in the extensional regime prior to tectonic inversion and $\sigma_{3}$ in the compressional regime after tectonic inversion. This constraint implies that the thickness of the overburden is not drastically changed during tectonic inversion. In the High-Ardenne case study, the assumption of a constant vertical principal stress is valid due to the limited compressibility of rocks both at maximum burial and during initial tectonic compression (i.e. the timing of bedding-normal and bedding-parallel veining, respectively). This constraint furthermore implies that the Poisson ratio ( $v)$ of the fractured sandstones (in the case study $v=0.25$ ) remains constant during inversion.

\section{Horizontal $\sigma_{T}$}

The tectonic inversion is induced by a horizontal tectonic stress $\sigma_{\mathrm{T}}$ that is consistent in orientation at the onset of orogeny. It is assumed to be parallel to one of the two horizontal principal stresses, $\sigma_{\mathrm{H}}$ or $\sigma_{\mathrm{h}}$, and increases in magnitude from extension to compression. If the tectonic stress $\sigma_{\mathrm{T}}$ is parallel to $\sigma_{1}, \sigma_{2}$ or $\sigma_{3}$ it is indicated as $\sigma_{1, \mathrm{~T}}, \sigma_{2, \mathrm{~T}}$ or $\sigma_{3, \mathrm{~T}}$ respectively (see Table 1 ). If the increasing $\sigma_{\mathrm{T}}$ is parallel to, for example, $\sigma_{\mathrm{H}}$, then $\sigma_{\mathrm{h}}$ will also indirectly increase due to the compressibility of the host rock (Mandl 2000) but at a lower rate than the increasing $\sigma_{\mathrm{H}}$.

$\sigma_{1}>\sigma_{2}>\sigma_{3}$ and $\sigma_{H}>\sigma_{h}$

The basic assumption is that both veining events in the case study reflect Andersonian stress regimes with one principal stress vertical $\left(\sigma_{\mathrm{V}}\right)$ and the other two principal stresses in the horizontal plane, parallel to the Earth's surface, and with $\sigma_{\mathrm{h}}$ being smaller than $\sigma_{\mathrm{H}}$ (Anderson 1951). By definition, $\sigma_{1}$ is larger than $\sigma_{2}$ which in turn exceeds $\sigma_{3}$. The latter implies that if $\sigma_{3}$ increases because of a consistent $\sigma_{\mathrm{T}}$ that is oriented parallel to $\sigma_{3}$, then $\sigma_{3, \mathrm{~T}}$ can become so large that it passes $\sigma_{2}$ in such a way that $\sigma_{3, \mathrm{~T}}$ becomes $\sigma_{2, \mathrm{~T}}$
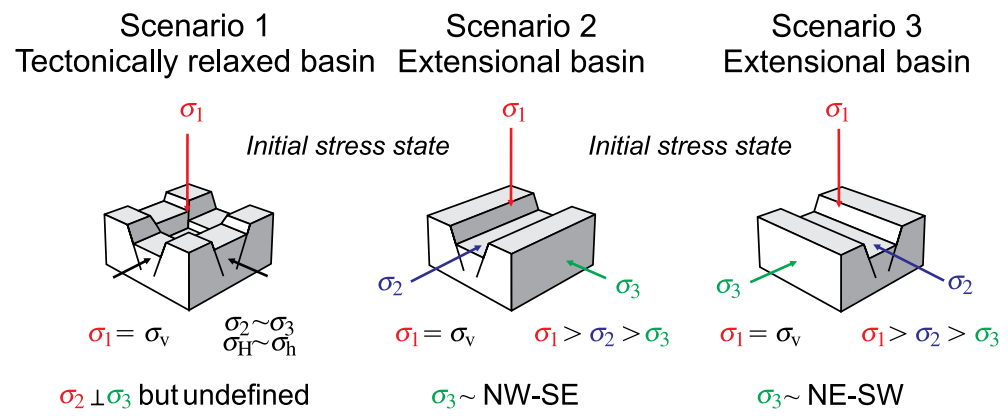

Fig. 5. Simplified representation of different basins as a starting point for the stress reconstructions. Scenario 1: tectonically relaxed basin that is able to extend in all directions without any predefined horizontal principal stress. Scenario 2: extensional basin that has a NE-SW-directed sedimentary basin elongation and extends perpendicular to $\sigma_{3}$. Scenario 3: extensional basin with a NE-SW-directed extension and a NW-SE elongation. Mirror image of scenario 2. 
Table 1. Abbreviations used in the stress-state reconstructions

\begin{tabular}{ll}
\hline Notation & \multicolumn{1}{c}{ Definition } \\
\hline$T$ & Tensile strength \\
$P_{\mathrm{f}}$ & Pore-fluid pressure \\
$\sigma^{\prime}$ & Effective stress \\
$\sigma_{\mathrm{V}}$ & Vertical principal stress \\
$\sigma_{\mathrm{T}}$ & Tectonic stress \\
$\sigma_{\mathrm{H}}$ & Maximum horizontal principal stress \\
$\sigma_{\mathrm{h}}$ & Minimum horizontal principal stress \\
$\sigma_{1}$ & Maximum principal stress \\
$\sigma_{2}$ & Intermediate principal stress \\
$\sigma_{3}$ & Minimum principal stress \\
$\sigma_{1, \mathrm{~T}}$ & Maximum principal stress increased by tectonic stress \\
$\sigma_{2, \mathrm{~T}}$ & Intermediate principal stress increased by tectonic stress \\
$\sigma_{3, \mathrm{~T}}$ & Minimum principal stress increased by tectonic stress \\
\hline
\end{tabular}

and $\sigma_{2}$ turns into $\sigma_{3}$. A similar transition can also occur between $\sigma_{2}$ and $\sigma_{1}$ if the tectonic principal stress $\sigma_{\mathrm{T}}$ influences $\sigma_{2}$. Only two kinds of tectonic stress transition can thus occur; one between $\sigma_{3}$ and $\sigma_{2}$ and one between $\sigma_{2}$ and $\sigma_{1}$. A direct transition between $\sigma_{3}$ and $\sigma_{1}$ is by definition not possible.

\section{Principal stresses}

All stresses tend to be compressional in the Earth's crust and true tensile stresses are uncommon at larger depths (Cosgrove 1995). In the different scenarios, principal stresses are used to illustrate the stress changes during tectonic inversion. During the whole evolution of inversion, it is assumed that hydrofracturing can take place continuously by reducing the effective stresses $\left(\sigma^{\prime}=\sigma-P_{\mathrm{f}}\right)$ by an elevated fluid pressure $\left(P_{\mathrm{f}}\right)$ that overcomes $\sigma_{3}$ to allow Mode I fracturing. In the High-Ardenne case study, the presence of overpressured fluids during the positive tectonic inversion is demonstrated by microthermometric studies, making this assumption valid. Differential stresses are thereby inferred to be low enough to allow extension fracturing. This constraint allows us to evaluate vein formation during each different stage.

\section{Vein rotation}

Although a slight reorientation of the original vein orientation has been observed from the SW (NESW; Bertrix) to the NE (NNE-SSW; Rursee) in the High-Ardenne slate belt (see Fig. 2), the orientation of the veins is kept constant for the simplicity of the constructed stress models. If veins form, they are assumed to be NE-SW. This simplified model allows the prediction of the specific moment during which the NE-SW vein set is formed.

\section{Mechanical models}

\section{Scenario 1: Tectonically relaxed basin}

In a first scenario, the stress-state reconstruction starts with a tectonically relaxed sedimentary basin in the extensional regime (Figs $5 \& 6$ ). The boundary conditions of a tectonically relaxed basin are such that $\sigma_{1}$ corresponds to the vertical overburden stress $\left(\sigma_{1} \sim \sigma_{\mathrm{V}}\right)$ and there is no distinction between the two horizontal principal stresses $\left(\sigma_{2}=\sigma_{3}\right.$ or $\sigma_{\mathrm{H}}=\sigma_{\mathrm{h}}$; see Cosgrove 1997, 2001). In a tectonically relaxed basin, $\sigma_{\mathrm{V}}$ and $\sigma_{\mathrm{H}}$ are related by common constraints of the rock in such way that $\sigma_{\mathrm{H}}=\sigma_{\mathrm{V}} /(m-1)$ in which $m$ is the reciprocal of the Poisson ratio $v$ (Price 1966).

Stage 1. A tectonic stress $\sigma_{\mathrm{T}}$ is assumed to be absent during subsidence in the tectonically relaxed basin. If extension veins could form due to elevated fluid pressures in stage 1 , there would be a tendency to form vertical veins but not in a certain direction. Theoretically, if the veins are close enough to interfere, polygonal vein arrays would develop at this specific stress state in which $\sigma_{\mathrm{V}}>\sigma_{\mathrm{H}}=\sigma_{\mathrm{h}}$ at low differential stresses smaller than $4 \mathrm{~T}$ (Cosgrove 1995, 1997).

Stage 2. As soon as a positive $\sigma_{\mathrm{T}}$ starts to increase in the basin at the onset of orogeny, $\sigma_{\mathrm{H}}$ and $\sigma_{\mathrm{h}}$ are defined as result of $\sigma_{\mathrm{T}}$ influencing one of the horizontal principal stresses. It depends on the NW-SE- or NE-SW-directed orientation of $\sigma_{\mathrm{T}}$ (1a or $1 \mathrm{~b}$ in Fig. 6, respectively) in which direction $\sigma_{\mathrm{H}} \sim \sigma_{2, \mathrm{~T}}$ will develop. Concomitant with the increasing $\sigma_{2, \mathrm{~T}}, \sigma_{3} \sim \sigma_{\mathrm{h}}$ increases but at a lower rate depending on the compressibility of the host rock. Eventually, the initial increase of $\sigma_{\mathrm{T}}$ results in a decrease of the differential stress $\sigma_{1} \sim \sigma_{3}$. Due to the protracted compression and increasing 


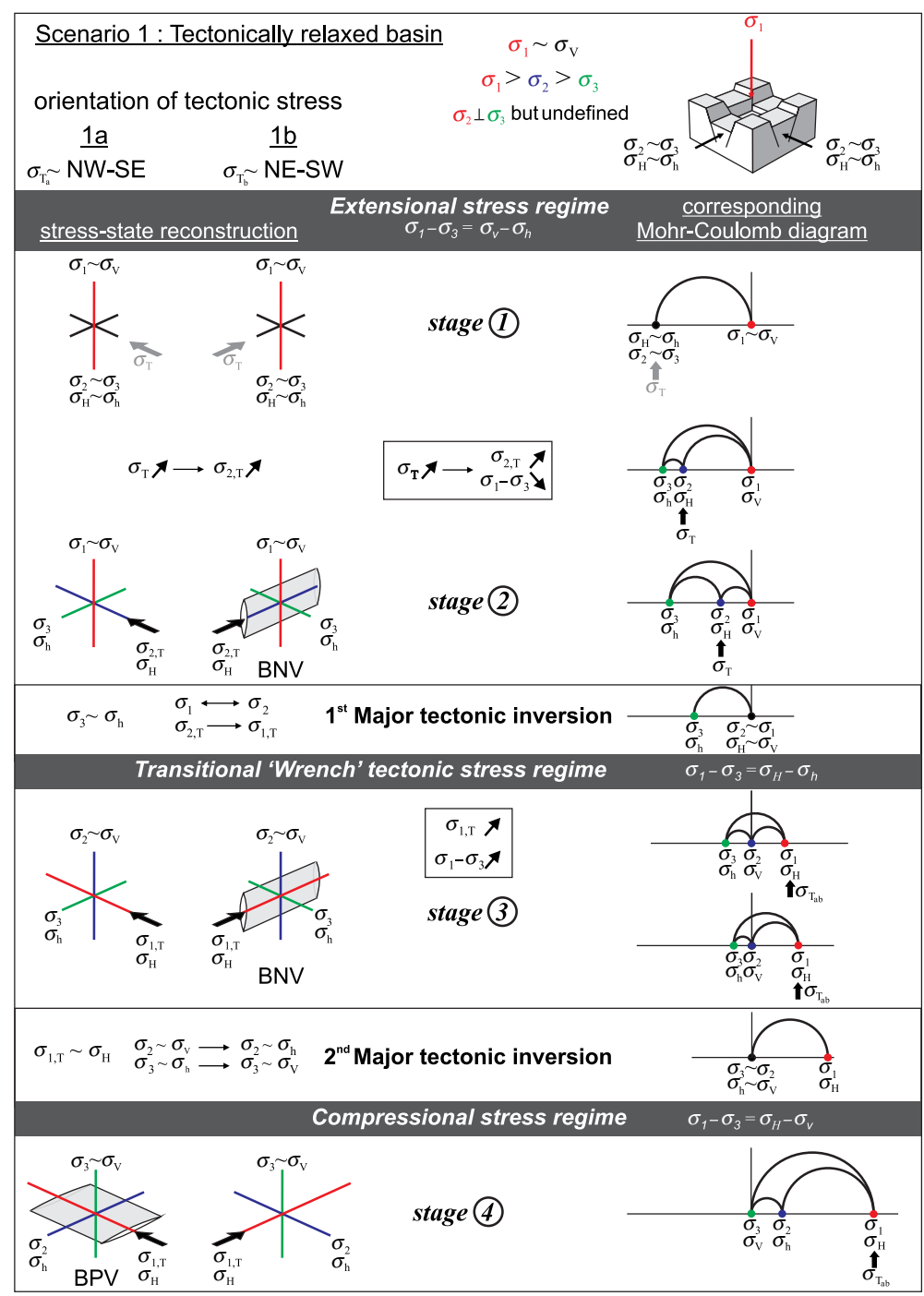

Fig. 6. Scenario 1 illustrating the 3D stress-state changes and corresponding Mohr circles of a tectonically relaxed basin that is shortened by a consistently oriented tectonic stress at the onset of orogeny and during compressional tectonic inversion. In the four stages, $\sigma_{1}-\sigma_{3}<4 T$. BNV, bedding-normal quartz veins; BPV, bedding-parallel quartz veins. The vertical line in the Mohr circles corresponds to $\sigma_{\mathrm{v}}$.

$\sigma_{\mathrm{T}}, \sigma_{2, \mathrm{~T}}$ approaches the magnitude of $\sigma_{1} \sim \sigma_{\mathrm{V}}$. When both stresses are subsequently equal in magnitude, a major tectonic inversion occurs during which $\sigma_{2, \mathrm{~T}}$ now becomes $\sigma_{1, \mathrm{~T}} \sim \sigma_{\mathrm{H}}$ while $\sigma_{1}$ turns into $\sigma_{2} \sim \sigma_{\mathrm{V}}$. The tectonic transition at this point implies a transition between two stress regimes, changing from an extensional regime into a 'wrench' tectonic regime with $\sigma_{2}$ as $\sigma_{\mathrm{V}}$. In the Mohr-Coulomb diagram (Fig. 6), this major tectonic inversion between the two stress regimes is illustrated by a switch point between $\sigma_{2}$ and $\sigma_{1}$ at the magnitude of $\sigma_{\mathrm{V}}$. At this switch point, $\sigma_{3}$ remains substantially smaller than $\sigma_{2}$ and $\sigma_{1}$ so that a residual differential stress remains present during this first major inversion and no isotropic stress condition is reached.

Stage 3. After this major tectonic inversion from the extensional into the 'wrench' tectonic regime, $\sigma_{1, \mathrm{~T}} \sim \sigma_{\mathrm{H}}$ passes the magnitude of $\sigma_{\mathrm{V}}$ and keeps increasing with increasing $\sigma_{\mathrm{T}}$. Similar to stage 2 , $\sigma_{3} \sim \sigma_{\mathrm{h}}$ increases concomitant with $\sigma_{1, \mathrm{~T}} \sim \sigma_{\mathrm{H}}$ but 
at a lower rate and approaches the magnitude of $\sigma_{2}$. As a result of the compressibility effect, the differential stress $\left(\sigma_{1}-\sigma_{3}\right)$ increases again. This shows that a differential stress state of zero is never reached during progressive compression, but that a residual differential stress at a value substantially smaller than $4 T$ remains present. A second major tectonic inversion occurs when $\sigma_{3} \sim \sigma_{\mathrm{h}}$ eventually exceeds $\sigma_{2} \sim \sigma_{\mathrm{V}}$. This transition is illustrated as a switch point in which $\sigma_{2}$ and $\sigma_{3}$ change in such way that $\sigma_{\mathrm{V}}$ now becomes $\sigma_{3}$ and $\sigma_{\mathrm{h}}$ becomes $\sigma_{2}$. This second switch point implies a tectonic inversion from a 'wrench' tectonic regime into a compressional tectonic regime, which occurs during increasing differential stress.

Stage 4. Finally, in the compressional regime, differential stress increases as long as $\sigma_{\mathrm{T}}$ does not stagnate and $\sigma_{1, \mathrm{~T}}$ keeps increasing. Eventually, the tectonic inversion from extension to compression of a tectonically relaxed basin in this scenario results in a triaxial stress state with three welldefined principal stresses.

\section{Scenario 2: Extensional basin with predefined $\sigma_{3} c . N W-S E$}

In a second scenario, we examine the effect of an increasing tectonic stress component applied on an extensional basin with a predefined structural orientation due to the preceding regional extension during sedimentary basin development. This scenario reflects a more common case in which the two horizontal stresses are different. The elongation of the basin is parallel to $\sigma_{2}$ and the basin opens perpendicular to $\sigma_{3}$ in a NW-SE direction (Figs $5 \mathrm{~b} \& 7$ ).

Stage 1. We examine two options in which $\sigma_{\mathrm{T}}$ varies from orthogonal $\left(\sigma_{\mathrm{Ta}} \sim \mathrm{NW}-\mathrm{SE}\right)$ to parallel $\left(\sigma_{\mathrm{Tb}} \sim\right.$ $\mathrm{NE}-\mathrm{SW}$ ) to the predefined structural elongation of the basin. The initial stress state prior to inversion is illustrated in the Mohr-Coulomb diagram by a universal triaxial stress state in which $\sigma_{1}$ corresponds to $\sigma_{\mathrm{V}}$. The initial starting point is equal for the two options; however, as soon as the additional $\sigma_{\mathrm{T}}$ starts to increase, the resulting stress state is different for the two options. When $\sigma_{\mathrm{Ta}}$ increases in a NW-SE-directed contraction (Fig. 7; option 2a), $\sigma_{3, \mathrm{Ta}} \sim \sigma_{\mathrm{h}}$ and $\sigma_{2} \sim \sigma_{\mathrm{H}}$ will both also increase although with a different rate because of the compressibility effect of the host rock. Because of this different rate, $\sigma_{3, \mathrm{Ta}} \sim \sigma_{\mathrm{h}}$ first approaches $\sigma_{2}$ and will afterwards become equal in magnitude to $\sigma_{2} \sim \sigma_{\mathrm{H}}$ at a certain moment. This equality is exemplified by a switch point in the Mohr-Coulomb diagram in which $\sigma_{3, \mathrm{Ta}}$ switches into $\sigma_{2, \mathrm{Ta}}$ and $\sigma_{2}$ becomes $\sigma_{3} \sim \sigma_{\mathrm{h}}$. This minor horizontal switch has no influence on the overall extensional stress regimes because $\sigma_{1}$ remains vertical and $\sigma_{2}$ and $\sigma_{3}$ remain in the horizontal plane corresponding to the two different horizontal principal stresses. However, if an increasing $\sigma_{\mathrm{Tb}}$ in a NE-SW-direction is applied to the predefined basin (Fig. 7; option 2b), then the previously described minor tectonic switch between $\sigma_{3}$ and $\sigma_{2}$ will never occur between stage 1 and stage 2 because $\sigma_{\mathrm{Tb}}$ immediately influences the initial $\sigma_{2}$.

Stage 2. In option $2 \mathrm{~b}$ (Fig. 7), $\sigma_{2, \mathrm{~Tb}}$ subsequently approaches $\sigma_{1}$ at a faster rate than the increase of $\sigma_{3}$ so that a minor horizontal switch between both principal stresses can never occur in the horizontal plane. Despite the difference between options $2 \mathrm{a}$ and $2 \mathrm{~b}$ in the extensional regime, eventually a major tectonic inversion occurs in both options. At the switch point in the Mohr-Coulomb diagram $\sigma_{2, \mathrm{~Tb}}$ equals $\sigma_{1}$, and during subsequent progressive compression they mutually change into a stress state in which $\sigma_{2} \sim \sigma_{\mathrm{V}}$ and $\sigma_{1}$ become $\sigma_{1, \mathrm{Tab}} \sim \sigma_{\mathrm{H}}$. This specific stress state has also been recognized during the tectonic inversion of a tectonically relaxed basin in scenario 1 and corresponds to a 'wrench' tectonic stress regime. In both options $2 \mathrm{a}$ and $2 \mathrm{~b}, \mathrm{a}$ residual differential stress remains present during this first major tectonic inversion because of the difference between $\sigma_{1}$ and $\sigma_{3}$. Although the stress state at the inversion is illustrated in one specific Mohr-Coulomb diagram for both options, there could be a substantial difference in differential stress between both options, with a lower differential stress state when $\sigma_{\mathrm{Ta}}$ first starts to work on $\sigma_{3}$ (option 2a) than if $\sigma_{\mathrm{Tb}}$ works on $\sigma_{2}$ (option 2b).

Stage 3. After the first major tectonic inversion $\sigma_{1, \mathrm{~T}} \sim \sigma_{\mathrm{H}}$ keeps increasing and, because of the compressibility effect of the host rock in the horizontal plane, $\sigma_{3} \sim \sigma_{\mathrm{h}}$ approaches $\sigma_{2} \sim \sigma_{\mathrm{V}}$. This leads to a second major tectonic inversion of the 'wrench' tectonic regime into the compressional tectonic regime in which $\sigma_{2}$ and $\sigma_{3}$ change so that $\sigma_{\mathrm{V}}$ becomes $\sigma_{3}$ and $\sigma_{\mathrm{h}}$ becomes $\sigma_{2}$

Stage 4. $\sigma_{3}$ eventually turns towards the vertical axis after the second tectonic inversion and $\sigma_{1, \mathrm{Tab}}$ and $\sigma_{2}$ are now both situated in the horizontal plane, as expected in the compressional stress regime. However, because of the orientation of the initial tectonic stress component $\sigma_{\mathrm{Ta}}$ or $\sigma_{\mathrm{Tb}}$, the eventual structural grain of the deformed basin is oriented differently in the two options.

\section{Scenario 3: Extensional basin with predefined $\sigma_{3} \sim N E-S W$}

In a third scenario, we examine the effect of a stress component that is applied on an extensional 


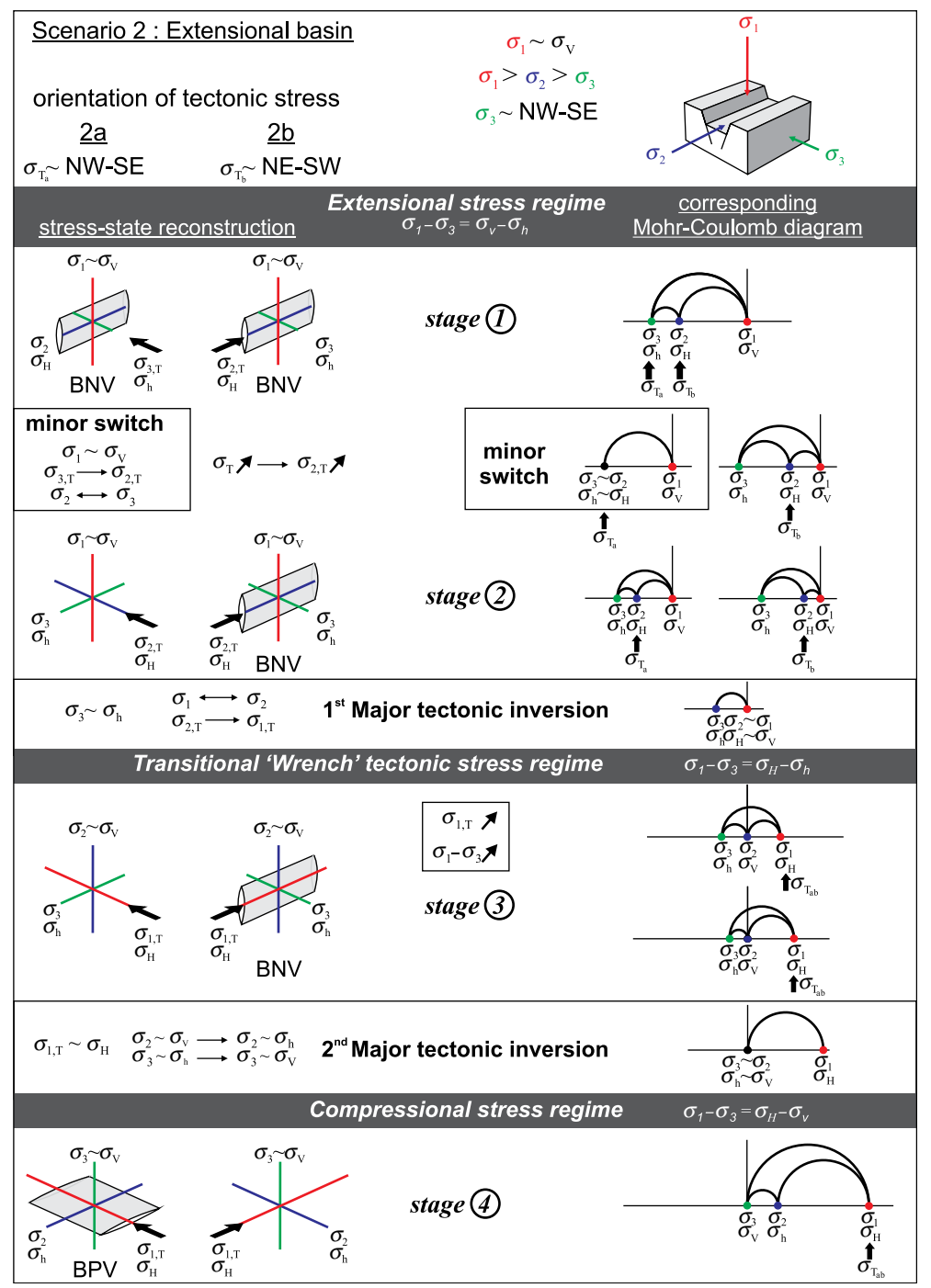

Fig. 7. Scenario 2 illustrating the 3D stress-state changes and corresponding Mohr circles of an extensional basin with a predefined $\sigma_{3}$ oriented NW-SE that is shortened by a consistently oriented tectonic stress at the onset of orogeny and during compressional tectonic inversion. Only scenario 2 a reflects the successive veining conditions in the High-Ardenne slate belt (North Eifel, Germany). In the four stages, $\sigma_{1}-\sigma_{3}<4 T$. BNV, bedding-normal quartz veins; $\mathrm{BPV}$, bedding-parallel quartz veins. The vertical line in the Mohr circles corresponds to $\sigma_{\mathrm{v}}$.

basin with a predefined structural orientation in which the elongation of the basin $\left(\sigma_{2}\right)$ is now oriented in a NE-SW direction and the basin opens perpendicular to $\sigma_{3}$ in a NW-SE-direction (Figs 5 \& 8). Similar to the second scenario, two options are investigated in which a consistent positive tectonic stress is applied on the predefined basin in a NW-SE-direction (i.e. $\sigma_{\mathrm{Ta}}$; Fig. 8, option $3 \mathrm{a}$ ) and in a NE-SW-direction (i.e. $\sigma_{\mathrm{Tb}}$; option $3 b)$.
Stage 1. The initial starting point is again equal for the two options, with $\sigma_{1}$ oriented vertically and two predefined horizontal $\sigma_{\mathrm{h}}$ and $\sigma_{\mathrm{H}}$.

Stage 2. As $\sigma_{\mathrm{T}}$ starts to increase, no minor tectonic switch occurs in option $3 \mathrm{a}$ if the applied tectonic stress $\sigma_{\mathrm{T}, \mathrm{a}}$ immediately works on $\sigma_{2, \mathrm{Ta}}$ and subsequently approaches $\sigma_{1} \sim \sigma_{\mathrm{V}}$ at the end of stage 2 . However, when a tectonic stress $\sigma_{\mathrm{T}, \mathrm{b}}$ increases parallel to $\sigma_{3}$ (option $3 \mathrm{~b}$ ), a minor tectonic switch 


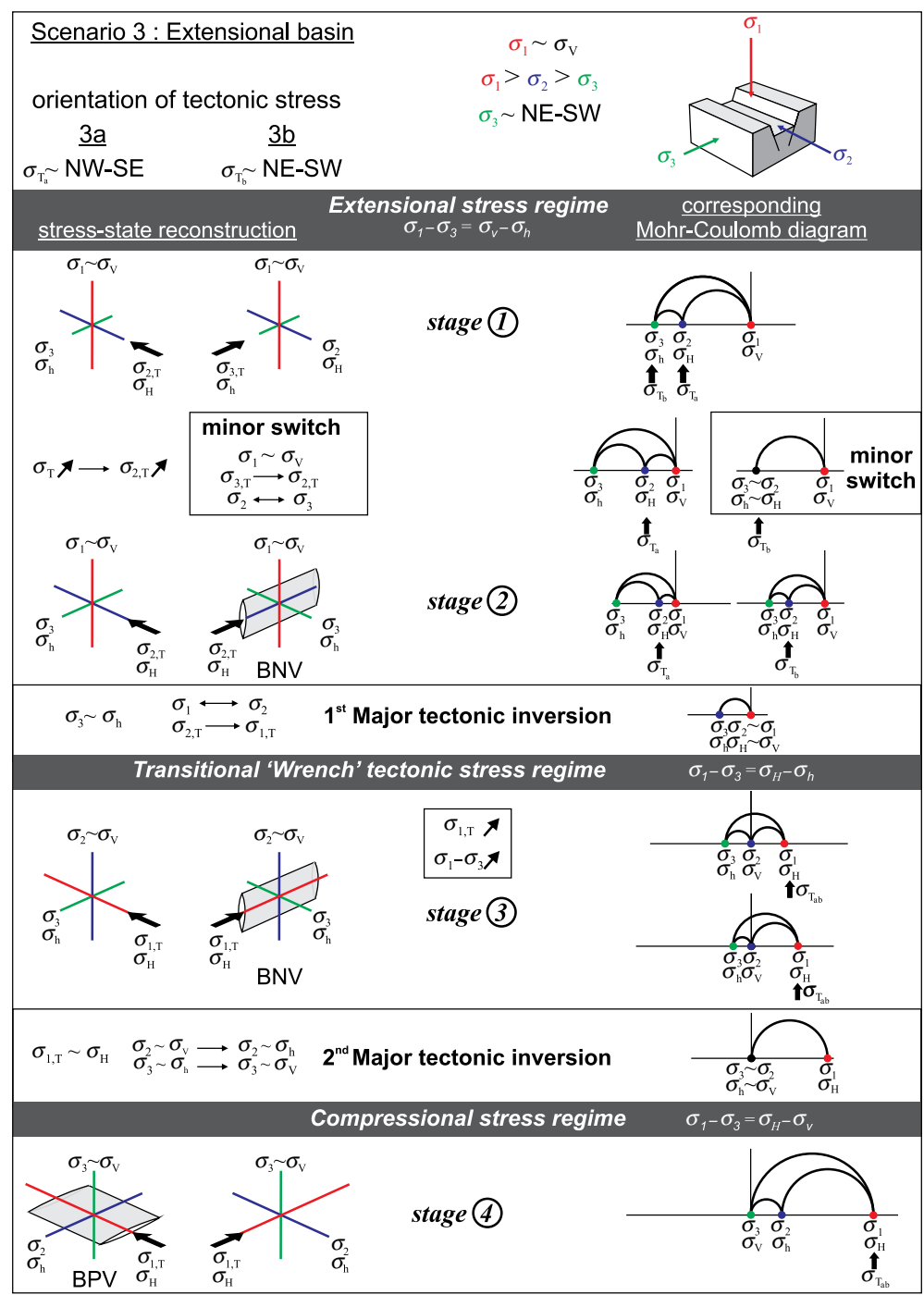

Fig. 8. Scenario 3 illustrating the 3D stress-state changes and corresponding Mohr circles of an extensional basin with a predefined $\sigma_{3}$ oriented NE-SW that is shortened by a consistently oriented tectonic stress at the onset of orogeny and during compressional tectonic inversion. In the four stages, $\sigma_{1}-\sigma_{3}<4 T$. BNV, bedding-normal quartz veins; BPV, bedding-parallel quartz veins. The vertical line in the Mohr circles corresponds to $\sigma_{\mathrm{v}}$.

occurs because $\sigma_{3, \mathrm{~Tb}} \sim \sigma_{\mathrm{h}}$ approaches $\sigma_{2}-\sigma_{\mathrm{H}}$ faster than $\sigma_{2}$ approaches $\sigma_{1} \sim \sigma_{\mathrm{V}}$. At the switch point of this minor tectonic inversion, $\sigma_{3, \mathrm{~Tb}}$ changes into $\sigma_{2, \mathrm{~Tb}}$ and $\sigma_{2}$ changes into $\sigma_{3} \sim \sigma_{\mathrm{h}}$ at constant $\sigma_{1} \sim \sigma_{\mathrm{V}}$. After this minor inversion in the horizontal plane, the differential stress further decreases because of increasing $\sigma_{\mathrm{Ta}}$ and $\sigma_{\mathrm{Tb}}$, eventually leading to the first major tectonic inversion at the end of stage 2 .

Stage 3. Similar to scenario 2 in both options 3 a and $3 \mathrm{~b}, \sigma_{2, \mathrm{~T}}$ equals $\sigma_{1}$ at the switch point and, during subsequent progressive compression, they mutually change at the point during which $\sigma_{2, \mathrm{~T}}$ turns towards the vertical $\sigma_{\mathrm{V}}$ and $\sigma_{1}$ becomes $\sigma_{1, \mathrm{~T}} \sim \sigma_{\mathrm{H}}$. The latter is indicative for a 'wrench' tectonic stress regime, in which extensional fracturing can occur at low differential stresses $>0$. With increasing differential stress at stage $3, \sigma_{3}$ approaches $\sigma_{2} \sim \sigma_{\mathrm{V}}$ which leads to the second major tectonic inversion.

Stage 4. After inversion $\sigma_{3}$ eventually switches towards the vertical $\sigma_{\mathrm{V}}$, corresponding to the compressional regime. 


\section{Discussion on fracturing and vein formation}

The stress-state evolution of a shortened sedimentary basin during compressional tectonic inversion, which is demonstrated by means of three different scenarios, yields several possibilities during which the two successive quartz vein sets of the HighArdenne case study can be formed. Concerning the timing of bedding-normal veining, the different stages during which the NE-SW bedding-normal extension veins can be formed are illustrated by means of the veins drawn in the different stress-state reconstructions (Figs 6-8).

Starting from a relaxed basin (scenario 1), the only possibility of forming the proper NE-SW vertical extension veins is if a NE-SW-directed $\sigma_{\mathrm{T}}$ decreases the differential stress during progressive compression until extensional fracturing is allowed (Fig. 6; stage 2; option 1b). Vein formation can occur prior to the first major tectonic inversion in the extensional regime, as well as after the major tectonic inversion in the transitional 'wrench' tectonic regime, due to the fact that $\sigma_{3}$ remains constant during the first major inversion (Fig. 6; stage 3; option 1b). Subsequently, bedding-parallel veins with pronounced NW-SE fabric can only be formed in the compressional regime during consistent NW-SE-directed compression (Fig. 6; stage 4; option 1a).

In an extensional basin with predefined NWSE-oriented $\sigma_{3}$ (scenario 2), bedding-normal veins can be formed in several phases. In stage 1 of both options $2 \mathrm{a}$ and $2 \mathrm{~b}$ (Fig. 7), the NW-SE extension of the basin is initially the sole factor that determines if $\mathrm{NE}-\mathrm{SW}$ bedding-normal veins can be formed under the circumstance that a NW-SE or NE-SW tectonic compression decreases the differential stress until extensional fracturing is allowed. After the predicted minor tectonic switch of $\sigma_{2}$ and $\sigma_{3}$ during progressive compression, the stress field is however misoriented to allow veining (Fig. 7; stage 2 ; option $2 \mathrm{a}$ ). In option $2 \mathrm{~b}$, no minor switch occurs because the tectonic stress $\sigma_{\mathrm{Tb}}$ is oriented parallel to $\sigma_{2}$, resulting in a stress field that remains constant during stages 1 and 2 . For similar reasons as in scenario $1, \mathrm{NE}-\mathrm{SW}$ veins can still be formed after the first major tectonic inversion in the 'wrench' transition regime due to the consistent $\sigma_{3}$ during inversion. Subsequently, the observed bedding-parallel veins are only formed in option $2 \mathrm{a}$, reflecting $\mathrm{NW}-\mathrm{SE}$ oriented compression.

Compression of a sedimentary basin in which the predefined $\sigma_{3}$ is NE-SW oriented (scenario 3), NE-SW veins can only be formed in stage 2 after the minor horizontal tectonic switch during NESW-directed contraction of $\sigma_{\mathrm{Tb}}$ (Fig. 8; stage 3; option $3 b$ ). Similar to the other two scenarios, veins can be formed both prior to as well as after the major tectonic inversion to a 'wrench' transitional tectonic regime. Similar to the other scenarios, the subsequent bedding-parallel veins with a NW-SE fabric are formed in the compressional regime after the second tectonic inversion, due to a NW-SE-oriented $\sigma_{\mathrm{Ta}}$ (Fig. 8; stage 4; option 3a).

Of the three different scenarios considered only option 2 a (Fig. 7) complies with the observations in the High-Ardenne case study, properly demonstrating how the NE-SW bedding-normal veins and subsequently the bedding-parallel veins with a $\mathrm{NW}-\mathrm{SE}$-directed internal fabric are formed. In this option, the model starts from an extensional basin that has a predefined structural NE-SW orientation (Fig. 5b) due to the geodynamic context of the Ardenne-Eifel basin on the passive margin of the Rhenohercynian Ocean. This particular basin configuration is corroborated by the identification of major basin-bounding NE-SW-trending normal fault systems indicated by stratigraphical mapping (see Mansy et al. 1999; Lacquement 2001). During extension of the basin, in which the load of the overburden corresponds to $\sigma_{1}$ in the basin, there is already a $\sigma_{\mathrm{T}}$ in a NW-SE direction parallel to $\sigma_{3}$ that causes an increase in the magnitude of $\sigma_{3}$ and consequently a decrease in differential stress, eventually leading to regionally consistent NE-SW extensional fracturing. This model furthermore implies that no veins are formed after the minor tectonic switch and in the transitional 'wrench' tectonic regime, because of misorientation of the stress regime.

The proper configuration in option 2 a allows the development of a stress-state reconstruction by means of several Mohr-Coulomb diagrams that illustrate successive fracturing and vein formation during the compressional tectonic inversion. Microthermometry testifies that maximum fluid overpressures of $c .190 \mathrm{MPa}$ and $c$. $205 \mathrm{MPa}$ are reached during bedding-normal and bedding-parallel extension veining, respectively (Van Noten 2011; Van Noten et al. 2011). The magnitude of the constant burial-related $\sigma_{\mathrm{v}}$ that corresponds to the load of the overburden at a depth of $c .7 \mathrm{~km}$ reflects a lithostatic pressure of $c$. $185 \mathrm{MPa}$, which is kept constant in the Mohr circle reconstructions (Fig. 9). During bedding-normal veining, the value of $\sigma_{\mathrm{h}}$ relates to $\sigma_{\mathrm{V}}$ in such way that (Cosgrove 1995; Cox et al. 2001):

$$
\sigma_{\mathrm{h}}=\sigma_{\mathrm{v}}\left(\frac{v}{1-v}\right)+\sigma_{\mathrm{T}}
$$

with a common Poisson ratio of $v \sim 0.25$ for sandstone (Mandl 2000).

In a tectonically relaxed basin in which $\sigma_{\mathrm{T}}=0$, this equation corresponds to $\sigma_{\mathrm{h}} \sim 62 \mathrm{MPa}$. However, the basin had a predefined geometry with 


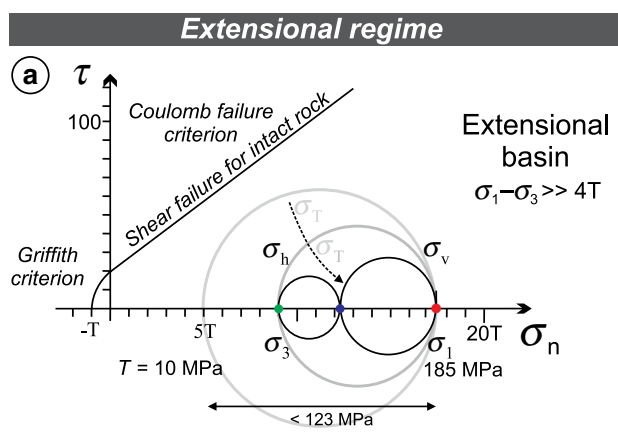

(b) Bedding-normal veining
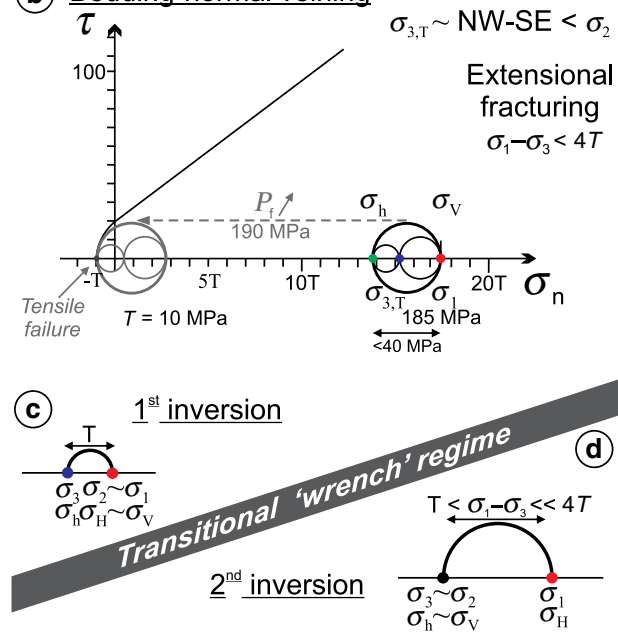

Compressional stress regime

(e)

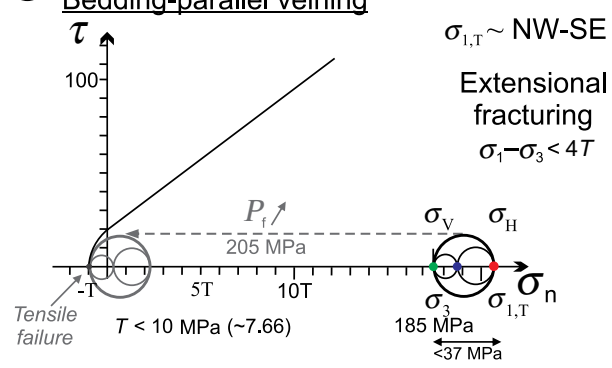

(f) Bedding-parallel veining

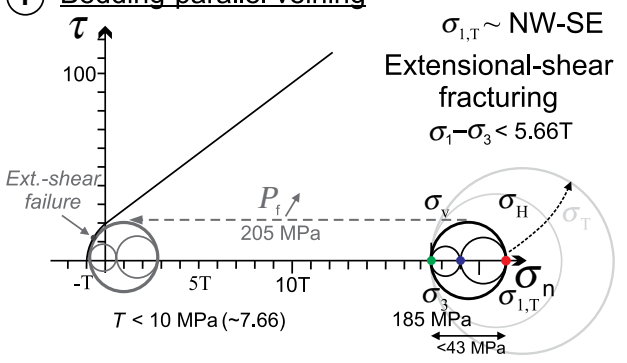

extension oriented $\mathrm{NW}-\mathrm{SE}$ perpendicular to $\sigma_{3} \sim \sigma_{\mathrm{h}}$, indicating that the magnitude of $\sigma_{3} \sim \sigma_{\mathrm{h}}$ of the basin in extension must therefore have been below $\sigma_{\mathrm{h}}=62 \mathrm{MPa}$. In such a configuration, the differential stress $\sigma_{1}-\sigma_{3}$ (that corresponds to $\sigma_{\mathrm{v}}-\sigma_{\mathrm{h}}$ ) is $c$. $123 \mathrm{MPa}$ (Fig. 9a). This value is too large to allow the formation of extension fractures developing at $\sigma_{1}-\sigma_{3}<4 T$ at $c .40 \mathrm{MPa}$ in which $T=10$ $\mathrm{MPa}$ is representative for intact sandstone. Therefore, $\sigma_{\mathrm{T}}$ acting on $\sigma_{3, \mathrm{~T}}$ (Fig. 7; option 2a; stage 1) must at least increase up to $83 \mathrm{MPa}$ in order to decrease the differential stress until the stress configuration of $\sigma_{1}-\sigma_{3, \mathrm{~T}}<40 \mathrm{MPa}$ is fulfilled (Fig. 9b). At this stage, a $P_{\mathrm{f}}$ of $c .190 \mathrm{MPa}$ is able to overcome $T$, allowing the formation of beddingnormal veins against the action of total pressure. This is illustrated by the fluid pressure that pushes the Mohr circle into the tensile domain (Fig. 9b). Note that the stress-state evolution from Figure $9 b$ is illustrated as a static reconstruction; in reality, this is a dynamic process in which $\sigma_{\mathrm{T}}$ increases with $P_{\mathrm{f}}$.

After the minor switch of $\sigma_{3, \mathrm{~T}}$ to $\sigma_{2, \mathrm{~T}}$, the first major tectonic inversion occurs (Fig. 9c). At this point, a residual differential stress remains present at an estimated value of approximately $\sigma_{1}-\sigma_{3}=$ $c$. $T$. After this stage, differential stress increases again in the transitional 'wrench' tectonic regime until the second tectonic inversion takes place at a differential stress above $T$ but below a substantial value of $4 T$ (Fig. 9d). After the reorientation of the principal stresses in the compressional regime, fracturing and vein formation takes place at a value of $\sigma_{1}-\sigma_{3}<30 \mathrm{MPa}$ for extensional failure (Fig. 9e) and slightly increases to $\sigma_{1}-\sigma_{3}<43 \mathrm{MPa}$ during subsequent extensional-shearfailure (Fig. 9f). Extensional failure therefore takes place at a lower differential stress in the compressional regime than compared to the extensional regime because of the lower tensile strength due to the bedding anisotropy $(T<10 \mathrm{MPa})$ during compression. Since $\sigma_{1}-\sigma_{3}=\sigma_{\mathrm{H}}-\sigma_{\mathrm{v}}$ and from Equation 1 modified for $\sigma_{\mathrm{H}}, \sigma_{\mathrm{T}}$ is allowed to rise up to values of $\sigma_{\mathrm{T}}=155 \mathrm{MPa}$ during extensional failure and $\sigma_{\mathrm{T}}=167 \mathrm{MPa}$ during extensional-shear failure in the compressional regime.

Fig. 9. Stress-state Mohr circle reconstruction of option 2a which best fits with the observations of the formation of the successive vein sets in the High-Ardenne slate belt. Stages $(\mathbf{a}-\mathbf{f})$ reflect the different stages of extensional brittle failure from the extensional regime over the intermediate 'wrench' tectonic regime into the compressional regime. See Table 1 for definitions of notation. BNV, bedding-normal veins; BPV, bedding-parallel veins. 
At this stage, the (supra-)lithostatic fluid pressure of $P_{\mathrm{f}}$ at $c .205 \mathrm{MPa}$ is able to overcome $T$. This is illustrated by the shift of the Mohr circle to the tensile domain, allowing failure when the Mohr circle hits the failure envelope. Furthermore, note that in a Mohr-Coulomb diagram supralithostatic failure is not illustrated as the Mohr circle cannot pass the Griffith criterion. Subsequently, $\sigma_{\mathrm{T}}$ increases during further contraction in the compressional regime (grey circle in Fig. 9f). A further Mohr circle reconstruction is prohibited as folds and cleavage subsequently developed, defining a plastic deformation which cannot be illustrated in a brittle failure diagram.

\section{General implications}

Apart from the regional implications, the different scenarios imply that if a basin is subjected to a tectonic compression, two or three tectonic switches are always necessary to explain the complex 3D tectonic inversion from an extensional to a compressional tectonic regime. The orientation of $\sigma_{\mathrm{T}}$ with respect to $\sigma_{3}$ is the sole factor that determines whether or not a minor horizontal tectonic switch between $\sigma_{2}$ and $\sigma_{3}$ will occur prior to the first major tectonic inversion. Furthermore, no matter the orientation of the basin geometry or the orientation of the increasing tectonic shortening, the presence of a transitional 'wrench' tectonic regime with a vertical $\sigma_{2}$ is always predicted during compressional tectonic inversion in a progressive deformation history. Although strike-slip related brittle features should be expected in such a stress configuration (Anderson 1951), the latter has to date never been observed or these features are not preserved in a shortened basin that has been subjected by a compressional tectonic inversion. This is possibly due to the (very) low differential stresses that remain present during inversion or due to the presence of previously formed structures (e.g. veins) that may form a strong anisotropy and may hamper the formation of new strike-slip related structures. Additionally, the time aspect during which tectonic inversion from extension to compression occurs may also play an important role. If, depending on the geodynamic setting of an area, a (relatively slow) tectonic inversion could take place during several millions years, a very long intermediate stage could occur in a specific situation during which differential stresses remain very small. In this specific case, structures related to the intermediate stage should be found.

To conclude, despite the fact that Sibson (1998, 2004) already mentioned that 'wrench' regimes have intermediate values bounded by the compressional and extensional regime criteria (i.e. at the zero differential stress line on Fig. 1), the presence of a transitional 'wrench' tectonic regime in between the extensional and compressional regime has to date not been visualized in a brittle failure mode plot. This study emphasizes that, depending on the value of $\sigma_{2}$, a whole range of possibilities are present during the tectonic inversion. Both the presence of an intermediate 'wrench' tectonic regime and the 3D complexity of a tectonic switch should therefore be taken into account in the construction of brittle failure mode plots. Tectonic inversions between stress regimes should not be considered as a single switch point, but should be subdivided in a double tectonic switch with a shortlived intermediate 'wrench' tectonic regime.

\section{Conclusions}

Although brittle failure mode plots are very useful to visualize the fluid pressure and stress-state evolution during tectonic inversion, they oversimplify the true stress switches in the Earth's crust during tectonic inversion at low differential stresses. In this study a 3D stress-state reconstruction of a compressional tectonic inversion has been carried out, based on two successive extensional quartz vein sets that are oriented normal and parallel to bedding and which occur in siliciclastic multilayers of the High-Ardenne slate belt (Belgium, Germany). The two vein occurrences are formed during the extensional and compressional regime and thus reflect Early Variscan tectonic inversion affecting the Ardenne-Eifel basin. In order to determine the stress-field orientation during compressional tectonic inversion, several 3D stress-state evolutions are reconstructed by applying a consistent tectonic stress component to a basin with a predefined structural orientation. By changing both the initial sedimentary basin geometry and the direction of the tectonic compression, several scenarios are developed; only one could explain the vein occurrences observed in the High-Ardenne slate belt. In the model which best fits the observations, the NESW bedding-normal extension veins can only be formed during a stress state in which a NWSE-directed tectonic stress $\sigma_{\mathrm{T}}$, oriented parallel to the opening direction $\left(\sigma_{3}\right)$ of the extensional Ardenne-Eifel basin, reduces the differential stress substantially in order to allow extensional veining. Bedding-parallel veins with the observed NW-SE internal fabric can subsequently only be formed under NW-SE-directed compression.

More generally, these stress-state reconstructions predict that if an increasing positive tectonic stress starts to compress a sedimentary basin at constant vertical principal stress (= overburden 
pressure), two or three tectonic stress switches are always necessary to explain the inversion from extension to compression depending on the orientation of $\sigma_{\mathrm{T}}$ with respect to the extension direction of the basin. If $\sigma_{\mathrm{T}}$ is oriented parallel to $\sigma_{3}$, a first minor stress switch occurs in the horizontal plane between $\sigma_{3}$ and $\sigma_{2}$. This minor switch is however absent if a tectonic stress increases in a tectonically relaxed basin or if it increases parallel to $\sigma_{2}$ (i.e. the elongation of the basin). During further progressive compression however, no matter the orientation of the basin geometry or the direction of the tectonic stress, in all the different scenarios an intermediate transitional 'wrench' tectonic stress regime is predicted in between the extensional and compressional regime. No evidence of this intermediate 'wrench' tectonic regime has yet been found in particular brittle features in a shortened basin that has been subjected to a tectonic inversion at low differential stress. Eventually, these reconstructions illustrate that if a basin experiences a tectonic inversion under triaxial stress conditions, stress transitions are more complex than classically represented. Ideally, the predicted intermediate 'wrench' tectonic regime should be implemented in the brittle failure mode plots, either in a third dimension or in separate brittle failure mode plots that illustrate the differences of $\sigma_{1}$ and $\sigma_{3}$ with $\sigma_{2}$.

This study has benefited from many discussions at the Anderson Stress Conference, September 2010, Glasgow and we would like to thank Z. Shipton, R. Sibson, D. Healy, R. Butler and H. Moir for organising and for editing this special publication. A. Fagereng and F. Trippetta are acknowledged for their interesting reviews which improved the quality of the paper. Additional discussion with S. Cox was very fruitful. This research was conducted within the project KAN 1.5.128.05 of the Fonds voor Wetenschappelijk Onderzoek-Vlaanderen and results from the $\mathrm{PhD}$ research of $\mathrm{KVN}$.

\section{References}

Anderson, E. M. 1951. The Dynamics of Faulting and Dyke Formation with Application to Britain. Oliver and Boyd, Edinburgh.

BLundell, D. J. 2002. The timing and location of major ore deposits in an evolving orogen: the geodynamic context. In: Blundell, D. J., Neubauer, E. \& VoN QuAdT, A. (eds) The Timing and Location of Major Ore Deposits in an Evolving Orogen. Geological Society, London, Special Publications, 204, 1-12.

Boullier, A.-M. \& Robert, F. 1992. Palaeoseismic events recorded in Archaean gold-quartz vein networks, Val d'Or, Abitibi, Quebec, Canada. Journal of Structural Geology, 14, 161-179.

Collettini, C., De Paola, N. \& Goulty, N. R. 2006. Switches in the minimum compressive stress direction induced by overpressure beneath a low-permeability fault zone. Terra Nova, 18, 224-231.
Cosgrove, J. W. 1995. The expression of hydraulic fracturing in rocks and sediments. In: AMEEN, M. S. (ed.) Fractography: Fracture Topography as a Tool in Fracture Mechanics and Stress Analysis. Geological Society, London, Special Publications, 92, 187-196.

Cosgrove, J. W. 1997. Hydraulic fractures and their implications regarding the state of stress in a sedimentary sequence during burial. In: SEngupta, S. (ed.) Evolution of Geological Structures in Micro- to Macroscales. Chapman \& Hall, London, 11-25.

Cosgrove, J. W. 2001. Hydraulic fracturing during the formation and deformation of a basin: a factor in the dewatering of low-permeability sediments. $A A P G$ Bulletin, 85, 737-748.

Cox, S. F. 1987. Antitaxial crack-seal vein microstructures and their relationship to displacement paths. Journal of Structural Geology, 9, 779-787.

Cox, S. F. 1995. Faulting processes at high fluid pressures: an example of fault valve behavior from the Wattle Gully Fault, Victoria, Australia. Journal of Geophysical Research, 100, $12841-12859$.

Cox, S. F. 2010. The application of failure mode diagrams for exploring the roles of fluid pressure and stress states in controlling styles of fracture-controlled permeability enhancement in fault and shear zones. Geofluids, 10, 217-233.

Cox, S. F., Knackstedt, M. A. \& Braun, J. 2001. Principles of Structural Control on Permeability and Fluid Flow in Hydrothermal Systems Structural Controls on Ore Genesis Reviews in Economic Geology. Society of Economic Geology, Boulder, 14, 1-24.

Crespi, J. M. \& Chan, Y.-C. 1996. Vein reactivation and complex vein intersection geometries in the Taconic Slate Belt. Journal of Structural Geology, 18, 933-939.

Debacker, T. N., Dumon, M. \& Matthys, A. 2009. Interpreting fold and fault geometries from within the lateral to oblique parts of slumps: a case study from the Anglo-Brabant Deformation Belt (Belgium). Journal of Structural Geology, 31, 1525-1539.

Fagereng, A., Remitti, F. \& Sibson, R. H. 2010. Shear veins observed within anisotropic fabric at high angles to the maximum compressive stress. Nature Geoscience, 3, 482-485.

Fielitz, W. 1992. Variscan transpressive inversion in the northwestern central Rhenohercynian belt of western Germany. Journal of Structural Geology, 14, $547-563$.

Fielitz, W. \& Mansy, J.-L. 1999. Pre- and synorogenic burial metamorphism in the Ardenne and neighbouring areas (Rhenohercynian zone, central European Variscides). Tectonophysics, 309, 227-256.

Gillespie, P. A., Walsh, J. J., Watterson, J., Bonson, C. G. \& Manzocchi, T. 2001. Scaling relationships of joint and vein arrays from The Burren, Co. Clare, Ireland. Journal of Structural Geology, 23, 183-201.

Healy, D. 2009. Anisotropy, pore fluid pressure and low angle normal faults. Journal of Structural Geology, 31, $561-574$.

Hilgers, C., Bücker, C. \& Urai, J. L. 2006a. Fossil overpressures compartments? a case study from the Eifel area and some general aspects. In: PHILLIPP, S., LEISS, B., Vollbrecht, A., Tanner, D. \& Gudmundsson, A. 
(eds) Symposium 'Tektonik, Struktur- und Kristallingeologie'. Universitätsdrucke Göttingen, Göttingen, Germany, 11, 87-89.

Hilgers, C., Kirschner, D. L., Breton, J.-P. \& Urai, J. L. 2006 $b$. Fracture sealing and fluid overpressures in limestones of the Jabal Akhdar dome, Oman mountains. Geofluids, 6, 168-184.

JACKSON, R. R. 1991. Vein arrays and their relationship to transpression during fold development in the Culm Basin, central south-west England. Proceedings of the Ussher Society, 7, 356-362.

Kenis, I. \& Sintubin, M. 2007. About boudins and mullions in the Ardenne-Eifel area (Belgium, Germany). Geologica Belgica, 10, 79-91.

Kenis, I., Sintubin, M., Muchez, Ph. \& Burke, E. A. J. 2002. The 'boudinage' question in the High-Ardenne Slate Belt (Belgium): a combined structural and fluid-inclusion approach. Tectonophysics, $\mathbf{3 4 8}$, 93-110.

Kenis, I., Muchez, P., Verhaert, G., Boyce, A. J. \& Sintubin, M. 2005. Fluid evolution during burial and Variscan deformation in the Lower Devonian rocks of the High-Ardenne slate belt (Belgium): sources and causes of high-salinity and $\mathrm{C}-\mathrm{O}-\mathrm{H}-\mathrm{N}$ fluids. Contributions to Mineralogy and Petrology, 150, $102-118$.

Lacquement, F. 2001. L'Ardenne Varisque. Déformation progressive d'un prisme sédimentaire pré-structuré, de l'affleurement au modèle de chaîne. Société Géologique du Nord, Lille, 29.

Laubach, S. E. \& Diaz-Tushman, K. 2009. Laurentian palaeostress trajectories and ephemeral fracture permeability, Cambrian Eriboll Formation sandstones west of the Moine Thrust Zone, NW Scotland. Journal of the Geological Society, London, 166, 349-362.

Laubach, S. E., Olson, J. E. \& Gale, J. F. W. 2004. Are open fractures necessarily aligned with maximum horizontal stresses? Earth and Planetary Science Letters, 222, 191-195.

MandL, G. 2000. Faulting in Brittle Rocks. An Introduction to the Mechanics of Tectonic Faults. SpringerVerlag Berlin, Heidelberg.

Manning, C. E. \& BIRD, D. K. 1991. Porosity evolution and fluid flow in the basalts of the Skaergaard magmahydrothermal system, East Greenland. American Journal of Science, 291, 201-257.

Mansy, J. L., Everaerts, M. \& De Vos, W. 1999. Structural analysis of the adjacent Acadian and Variscan fold belts in Belgium and northern France from geophysical and geological evidence. Tectonophysics, 309, 99-116.

Mazzarini, F., Isola, I., Ruggieri, G. \& Boschi, C. 2010. Fluid circulation in the upper brittle crust: thickness distribution, hydraulic transmissivity fluid inclusion and isotopic data of veins hosted in the Oligocene sandstones of the Macigno Formation in southern Tuscany, Italy. Tectonophysics, 493, $118-138$.

Meilliez, F. \& Mansy, J.-L. 1990. Déformation pelliculaire différenciée dans une série lithologique hétérogène: le Dévono-Carbonifère de l'Ardenne. Bulletin de la Société géologique de France, 6, 177-188.
Muchez, Ph., Sintubin, M. \& Swennen, R. 2000. Origin and migration pattern of palaeofluids during orogeny: discussion on the Variscides of Belgium and northern France. Journal of Geochemical Exploration, 69-70, 47-51.

Nielsen, P., Swennen, R., Muchez, Ph. \& Keppens, E. 1998. Origin of Dinatian zebra dolomites south of the Brabant-Wales Massif, Belgium. Sedimentology, 45, 727-743.

Price, N. J. 1966. Fault and Joint Development in Brittle and Semi-Brittle Rock. Pergamon Press, Oxford.

RAmsaY, J. G. 1980. The crack-seal mechanism of rock deformation. Nature, 284, 135-139.

SECOR, D. T. 1965. Role of fluid pressure in jointing. American Journal of Sciences, 263, 633-646.

SibSON, R. H. 1990. Conditions for fault-valve behaviour. In: Knipe, R. J. \& Rutter, E. H. (eds) Deformation Mechanisms, Rheology and Tectonics. Geological Society, London, Special Publications, 54, 15-28.

Sibson, R. H. 1995. Selective fault reactivation during basin inversion: potential for fluid redistribution through fault-valve action. In: Buchanan, J. G. \& Buchanan, P. G. (eds) Basin Inversion. Geological Society, London, Special Publications, 88, 3-19.

Sibson, R. H. 1998. Brittle failure mode plots for compressional and extensional tectonic regimes. Journal of Structural Geology, 20, 655-660.

SibSON, R. H. 2000. Tectonic controls on maximum sustainable overpressure: fluid redistribution from stress transition. Journal of Geochemical Exploration, 6970, 471-475.

Sibson, R. H. 2004. Controls on maximum fluid overpressure definitions conditions for mesozonal mineralisation. Journal of Structural Geology, 26, $1127-1136$.

Stets, J. \& Schafer, A. 2009. The Siegenian delta: landsea transitions at the northern margin of the Rhenohercynian Basin. In: Koniggshof, P. (ed.) Devonian Change: Case Studies in Palaeogeography and Palaeoecology. Geological Society, London, Special Publications, 314, 37-72.

Stowell, J. F. W., Watson, A. P. \& Hudson, N. F. C. 1999. Geometry and populations systematics of a quartz vein set, Holy Island, Anglesey, North Wales. In: McCaffrey, K. J. W., Lonergan, L. \& Wilkinson, J. J. (eds) Fractures, Fluid Flow and Mineralisation. Geological Society, London, Special Publications, 155, 17-33.

Teixell, A., Durney, D. W. \& Arboleya, M.-L. 2000. Stress and fluid control on décollement within competent limestone. Journal of Structural Geology, 22, 349-371.

Tunks, A. J., Selley, D., Rogers, J. R. \& Brabham, G. 2004. Vein mineralization at the Damang Gold Mine, Ghana: controls on mineralization. Journal of Structural Geology, 26, 1257-1273.

VAN BAElen, H. 2010. Dynamics of a Progressive vein Development During the Late-Orogenic Mixed Brittle-Ductile Destabilisation of a Slate Belt. Examples of the High-Ardenne Slate Belt (Herbeumont, Belgium) Aardkundige mededelingen series, 24, 1-221.

Van Baelen, H. \& Sintubin, M. 2008. Kinematic consequences of an angular unconformity in simple shear: an 
example from the southern border of the Lower Palaeozoic Rocroi inlier (Naux, France). Bulletin de la Société géologique de France, 179, 73-87.

VAN Noten, K. 2011. Stress-State Evolution of the Brittle Upper Crust during Early Variscan Tectonic Inversion as Defined by Successive Quartz Vein-Types in the High-Ardenne Slate Belt, Germany. Aardkundige mededelingen series, 28, 1-241.

Van Noten, K. \& Sintubin, M. 2010. Linear to nonlinear relationship between vein spacing and layer thickness in centimetre- to decimetre-scale siliciclastic multilayers from the High-Ardenne slate belt (Belgium, Germany). Journal of Structural Geology, 32, 377-391.

Van Noten, K., Hilgers, C., Urai, J. L. \& Sintubin, M. 2008. Late burial to early tectonic quartz veins in the periphery of the High-Ardenne slate belt (Rursee, North Eifel, Germany). Geologica Belgica, 11, 179-198.

Van Noten, K., Berwouts, I., Muchez, Ph. \& SintuBIN, M. 2009. Evidence of pressure fluctuations recorded in crack-seal veins in low-grade metamorphic siliciclastic metasediments, Late Palaeozoic
Rhenohercynian fold-and-thrust belt (Germany). Journal of Geochemical Exploration, 101, 106.

Van Noten, K., Muchez, Ph. \& Sintubin, M. 2011. Stress-state evolution of the brittle upper crust during compressional tectonic inversion as defined by successive quartz vein types (High-Ardenne slate belt, Germany). Journal of the Geological Society, London, 168, 407-422.

Von WinTERFELD, C.-H. 1994. Variszische Deckentektonik und devonische Beckengeometrie der Nord-Eifel Ein quantitatives Modell (Profilbilanzierung und Strain-Analyse im Linksrheinischen Schiefergebirge). Aachener Geowissenschaftliche Beiträge, RWTH Aachen, 2, 1-319.

Weber, K. 1981. The structural development of the Rheinische Schiefergebirge. Geologie en Mijnbouw, 60, 149-159.

Wiltschko, D. V., Lambert, G. R. \& Lamb, W. 2009. Conditions during syntectonic vein formation in the footwall of the Absaroka Thrust Fault, IdahoWyoming-Utah fold and thrust belt. Journal of Structural Geology, 31, 1039-1057. 